\title{
COMPARISON OF INTRA-ARTICULAR INJECTION THERAPY TO PHYSIOTHERAPY TECHNIQUES IN MANAGEMENT OF SHOULDER IMPINGEMENT SYNDROME.
}

\footnotetext{
1. MBBS, FCPS (Orth) Assistant Professor Department of Orthopedics Independent Medical College, Faisalabad, Pakistan.

2. BSPT, PPDPT M.Phil Consultant Physiotherapist Department of Physiotherapy Independent University Hospital, Faisalabad, Pakistan

3. MBBS, FCPS Orth Senior Registrar Department of Orthopedic Allied Hospital, Faisalabad.

4. Pharm-D, M.Phil, Government College University, Faisalabad.
}

\section{Correspondence Address:}

Dr. Hafiz Salman Saeed

Department of Orthopedics Independent Medical College,

Faisalabad, Pakistan.

hafizsalman167@gmail.com

Article received on: 20/03/2019

Accepted for publication: $15 / 05 / 2019$

Received after proof reading: 22/05/2019

\begin{abstract}
Hafiz Salman Saeed ${ }^{1}$, Muquduss Asif ${ }^{2}$, Muhammad Sajjad Iqbal ${ }^{3}$, Iqra Fayyaz ${ }^{4}$
\end{abstract}
\begin{abstract}
Shoulder impingement syndrome is umbrella term that covers rotator cuff syndrome, tendinitis of muscles of rotator cuff and bursitis in shoulder region. Usually this syndrome is treated conservatively. The treatment options are corticosteroid injections, medical treatment and physical therapy, of which, the most common are injection therapy and physical therapy. Injection therapy is carried out by orthopedic surgeons. However, which treatment is most effective in terms of symptoms relieving and cost effectiveness, yet conflicting. Study Design: Randomized Controlled Trial. Setting: Independent University Hospital, Faisalabad. Period: $1^{\text {st }}$ July 2017 to $30^{\text {th }}$ June 2018. Materials and Methods: Comparing effects of two treatments for shoulder impingement syndrome; sub armorial steroid injection, the control group and manual physical therapy, the treatment group. Primary outcomes were Shoulder Pain and Disability Index (SPADI), to measure endpoint differences. Secondary outcomes included changes in Global Rating of Change (GRC) scale and Numeric Pain Rating Scale (NPRS) scores. Trial was conducted in one clinical setup. The collected data was analyzed by Statistical Package of Social Sciences (SPSS 20.00). Results: At baseline of group physical therapy $19(95 \%)$ reported severe and $1(5 \%)$ moderate level of pain, at numeric rating pain scale. At post treatment of group injection therapy $19(95 \%)$ reported severe and $1(5 \%)$ moderate level of pain, at numeric rating pain scale. At follow up of group injection therapy $19(95 \%)$ reported severe and $1(5 \%)$ moderate level of pain, at numeric rating pain scale. At follow up of treatment physical therapy all patients mild level of pain, at numeric rating pain scale. Conclusion: Injection therapy treatment is more effective in improving shoulder impingement syndrome in terms of pain and function than that of physical therapy treatment.
\end{abstract}

Key words: Corticosteroid, Injection Therapy, Physiotherapy, Shoulder Impingement Syndrome.

Article Citation: Saeed HS, Asif M, Iqbal MS, Fayyaz I. Comparison of intra-articular injection therapy to physiotherapy techniques in management of shoulder impingement syndrome. Professional Med J 2019; 26(6):870-875.

DOI: 10.29309/TPMJ/2019.26.05.3432

\section{INTRODUCTION}

Shoulder impingement syndrome is umbrella term that covers rotator cuff syndrome, tendinosis of muscles of rotator cuff and bursitis in shoulder region. ${ }^{1}$ Overhead activity and repeated movements are risk for development of impingement syndrome, for example lifting, painting, playing tennis and swimming. Bone and joint abnormalities are other risk factors. Every 5 to 30 patients from 1000 are found with this condition $^{2}$

\section{Shoulder impingement syndrome affects} activities of daily living such as reaching behind back, reaching overhead, wearing and getting off clothes etc. These are the typical symptoms of impingement syndrome in shoulder. If not treated shoulder impingement syndrome leads inflammation of rotator cuff muscles and subacromion bursa. If rotator cuff tear involves in later stages, it results in significant weakness and may make it difficult for the patient to lift the arm. Still in worse cases, rupture of bicep tendons also has been reported.

Usually the medical history and clinical presentations are main means of diagnosis. Plain radiograph are useful ruling out arthritic changes. 
Also it may reveal any bone spurs or changes in bone density and contour. Usually this syndrome is treated conservatively. ${ }^{3}$

The treatment options are corticosteroid injections, medical treatment and physical therapy, of which, the most common are injection therapy and physical therapy. ${ }^{4}$ Injection therapy is carried out by orthopedic surgeon. ${ }^{5}$ However, which treatment is most effective in terms of symptoms relieving and cost effectiveness, yet conflicting. Clinical practice guidelines of many clinical placements recommend injection therapy in case of rotator cuff tear only. ${ }^{6}$

Recently there found different systematic reviews having differing conclusions on efficacy of different treatment strategies. Where many studies show effectiveness of manual physical therapy in shoulder impingement syndrome, two recent systematic reviews show no evidence of additional benefits in comparison of other treatment strategies, which shows need of further research in this aspect. Also there found no empirical data about effective practice patterns and timings. Studies also suggest that injection therapy is more effective strategy initially while in longer run physical therapy is best strategy. There still found other studies advocated that injection therapy and physiotherapy techniques in combination are effective strategies.

Another study found figuring out comparison of Corticosteroid injections (CSI) with manual therapy techniques. There were variety of reports from systematic reviews. Long term efficacy of CSI found questionable. A trial found estimating the cost effectiveness of subacromial corticosteroid injection in combination and alone. This trial, however, concluded that combination therapy is more cost effective. ${ }^{8-9}$

Whileanother study concluded and recommended corticosteroid injections as primary care strategy while manual therapy as secondary long run strategy in managing shoulder impingement syndrome. There is less evidence about long term efficacy of both manual therapy treatment and corticosteroid injection therapy in improving flexibility, strength and functional status after shoulder impingement syndrome.

Another single blind randomized controlled trial conducted for comparing effects of therapeutic exercise, manipulation and steroid injections. It came with conclusion that for shoulder girdle related problems manipulation was with significant effects, while for synovial based problems injection therapy with steroid has significant effects. A pragmatic randomized clinical trial found debating comparison of different care strategies in managing shoulder impingement syndrome, such as steroid therapy with or without exercise therapy. It followed up patients for one year and concluded that after 12 months, outcomes of both combination therapy and exercise therapy alone are same. So to manage pain injection therapy may be taken in earlier stages but eradicate problem properly and make the treatment cost effective, exercise therapy should be carried on. ${ }^{13}$

\section{OBJECTIVE}

To determine the outcomes of Intra-Articular Injection Therapy compared to Physiotherapy Techniques in Management of Shoulder Impingement Syndrome.

\section{MATERIAL AND METHOD Study Design}

Randomized Controlled Trial, comparing effects of two treatments for shoulder impingement syndrome; sub armorial steroid injection and manual physical therapy.

\section{Trial Setting}

Trial was conducted in Independent University Hospital, Faisalabad.

\section{Duration of Study}

$1^{\text {st } J u l y ~} 2017$ to $30^{\text {th }}$ June 2018 .

\section{Inclusion Criteria}

Consecutive Patient age 18-65 years with a primary symptom of unilateral shoulder pain.

\section{Exclusion Criteria}

Patients with shoulder dislocation, fracture, 
adhesive capsulitis, subacromial injection therapy or physiotherapy for shoulder pain, systemic or neurological disease as cause of shoulder pain, full thickness tear, less than $20 \%$ baseline SPADI score, shoulder symptom with cervical spondylosis.

\section{Primary and Secondary Outcome Measures}

Primary outcomes were Shoulder Pain and Disability Index (SPADI), to measure endpoint differences.

\section{Shoulder Pain and Disability Index (SPADI)}

It is a 100-point, 13-item, self-administered questionnaire that is broken into 2 subscales: a 5 item pain scale and an eight item disability scale. It is valid and responsive, can discriminate between improving and worsening status. ${ }^{10}$

Secondary outcomes will include changes in Global Rating of Change (GRC) scale and Numeric Pain Rating Scale (NPRS) scores.

\section{Global Rating of Change (GRC) scale}

It is an instrument that assess overall perceived changes in the patient's quality of life. ${ }^{11}$ It also gives a valid assessment of change in patients' perceived status. ${ }^{12}$

\section{Numeric Pain Rating Scale (NPRS)}

It is an 11-point NPRS ranging from 0 (no pain) to 10 (worst imaginable pain) was used to assess pain intensity. ${ }^{13}$ This scale has been demonstrated to be a reliable, generalizable, and internally consistent measure of clinical and experimental pain intensity. ${ }^{14}$

SPIRIT (Standard Protocol Items: Recommendations for Interventional Trials) were followed for trial guidelines ${ }^{15}$ and CONSORT (Consolidated Standards of Reporting Trials) for reporting trial. ${ }^{16}$

\section{RESULTS}

Age of patient's wise distribution shows 5 (25\%) less than 35 to 40,4 (20\%) more than 40 to 45,4 (20\%) more than 45 to $50,4(20 \%)$ more than 50 to 55 and $3(15 \%)$ more than 55 to 60 out of 20 Patients taking Injection therapy. Age of Patients taking physical therapy treatment $9(45 \%)$ less than 35 to $40,6(30 \%)$ more than 40 to 45 and 5 (25\%) more than 45 to 50 out of 20 patients.

Gender wise distribution of the patients taking physical therapy $16(80 \%)$ female and $4(20 \%)$ male out of 20 patients. Gender wise distribution shows $7(35 \%)$ were male and $13(65 \%)$ were female out of 20 Patients taking Injection therapy treatment. At baseline all patients in injection therapy group reported severe level of pain, at numeric rating pain scale. At baseline of group physical therapy 19(95\%) reported severe and $1(5 \%)$ moderate level of pain, at numeric rating pain scale.

At post treatment of group injection therapy $19(95 \%)$ reported severe and $1(5 \%)$ moderate level of pain, at numeric rating pain scale. At post treatment of group physical therapy $16(80 \%)$ reported moderate and $4(20 \%)$ mild level of pain, at numeric rating pain scale. At follow up of treatment physical therapy all patients mild level of pain, at numeric rating pain scale.

\begin{tabular}{|c|c|c|c|}
\hline \multicolumn{2}{|c|}{ Treatment Type } & $\mathbf{F}$ & Percentage \\
\hline \multirow{3}{*}{$\begin{array}{l}\text { Physical } \\
\text { Therapy }\end{array}$} & Less than 35 to 40 & 9 & 45 \\
\hline & More than 40 to 45 & 5 & 25 \\
\hline & More than 45 to 50 & 6 & 30 \\
\hline \multicolumn{2}{|l|}{ Total } & 20 & 100 \\
\hline \multirow{5}{*}{$\begin{array}{l}\text { Injection } \\
\text { Therapy }\end{array}$} & Less than 35 to 40 & 5 & 25 \\
\hline & More than 40 to 45 & 4 & 20 \\
\hline & More than 45 to 50 & 4 & 20 \\
\hline & Less than 50 to 55 & 3 & 15 \\
\hline & More than 55 to 60 & 4 & 20 \\
\hline \multicolumn{2}{|l|}{ Total } & 20 & 100 \\
\hline \multicolumn{4}{|c|}{ Table-I. Age of patients } \\
\hline \multicolumn{2}{|c|}{ Treatment Type } & $\mathbf{F}$ & Percentage \\
\hline \multirow{2}{*}{$\begin{array}{l}\text { Physical } \\
\text { Therapy }\end{array}$} & Male & 4 & 20 \\
\hline & Female & 16 & 80 \\
\hline \multicolumn{2}{|l|}{ Total } & 20 & 100 \\
\hline \multirow{2}{*}{$\begin{array}{l}\text { Injection } \\
\text { Therapy }\end{array}$} & Male & 7 & 35 \\
\hline & Female & 13 & 65 \\
\hline \multicolumn{2}{|l|}{ Total } & 20 & 100 \\
\hline \multicolumn{4}{|c|}{ Table-II. Gender of patients } \\
\hline
\end{tabular}

Professional Med J 2019;26(6):870-875.

www.theprofesional.com

872 


\begin{tabular}{|l|l|c|c|}
\hline \multicolumn{2}{|c|}{ Treatment Type } & F & Percentage \\
\hline $\begin{array}{l}\text { Physical } \\
\text { Therapy }\end{array}$ & Moderate (4-6) & 1 & 5 \\
\hline Total & Severe (7-10) & 19 & 95 \\
\hline \multicolumn{2}{|l|}{} \\
\hline $\begin{array}{l}\text { Injection } \\
\text { Therapy }\end{array}$ & Severe (7-10) & 20 & 100 \\
\hline
\end{tabular}

Table-III. Numeric pain rating scale: Baseline value

\begin{tabular}{|l|l|c|c|}
\hline \multicolumn{2}{|c|}{ Treatment Type } & F & Percentage \\
\hline $\begin{array}{l}\text { Physical } \\
\text { Therapy }\end{array}$ & Mild (0-3) & 4 & 20 \\
\cline { 2 - 4 } & Moderate (4-6) & 16 & 80 \\
\hline Total & 20 & 100 \\
\hline \multirow{2}{*}{$\begin{array}{l}\text { Injection } \\
\text { Therapy }\end{array}$} & Moderate (4-6) & 19 & 95 \\
\cline { 2 - 4 } & Severe (7-10) & 1 & 5 \\
\hline & Total & 20 & 100 \\
\hline
\end{tabular}

Table-IV. Numeric pain rating scale: Post treatment value

\begin{tabular}{|l|l|c|c|}
\hline \multicolumn{2}{|c|}{ Treatment Type } & F & Percentage \\
\hline $\begin{array}{l}\text { Injection } \\
\text { Therapy }\end{array}$ & Mild (0-3) & 18 & 90 \\
\cline { 2 - 4 } & Moderate(4-6) & 2 & 10 \\
\hline Total & 20 & 100 \\
\hline \multicolumn{2}{|c|}{$\begin{array}{l}\text { Physical } \\
\text { Therapy } \\
\text { Table-V. Numeric pain rating scale: Follow up value }\end{array}$} \\
\hline
\end{tabular}

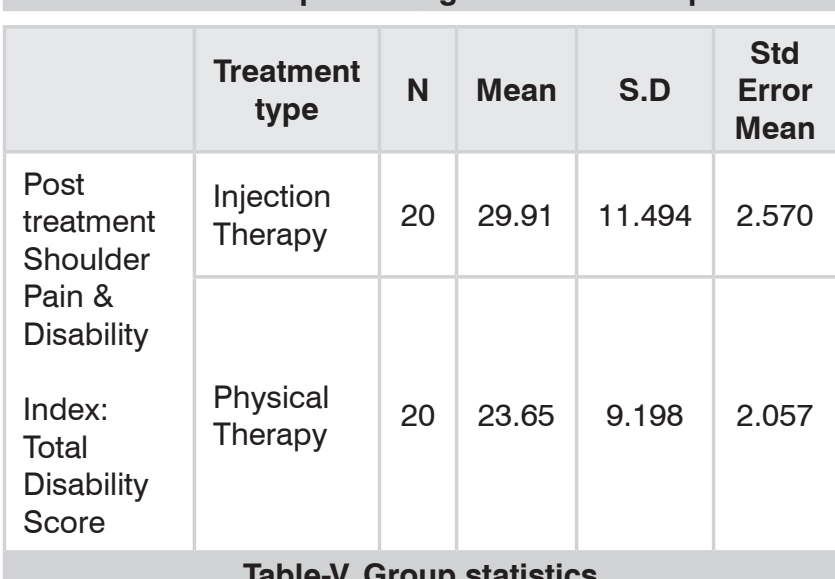

\section{DISCUSSION}

Patients either treated with physiotherapy, local steroid injection or a combination of both these options all had improvement in pain and improved range of motion. In short and long term prospectus, injection therapy had increased outcome than that of physiotherapy. There was no definite evidence of type II statistical error. Our findings are comparable with other studies for the painful stiff shoulder. There was little long term advantage in using different treatment option such as ice therapy, intra-articular steroid, range of motion at shoulder or no treatment. But the improvement in pain and range of motion by steroid infection only occur in early stage of disease..$^{17-19}$

Some studies showed that there was no difference in physiotherapy plus steroid injection against physiotherapy alone. ${ }^{4}$ One study showed that there was no difference between acupuncture, steroid injection \& placebo. ${ }^{5}$ One study showed that there was no difference in pain relief after treatment with steroid injection of placebo. ${ }^{6}$ There was no additional benefit when intra articular steroid were given along with physiotherapy. This shows that improvement in range of motion cannot be maximized above a certain level.

There was no complication with either physiotherapy or intra articular steroid injection. Rupture tendon or infection were less likely with intra articular injection. Problem with physiotherapy are very uncommon. The problem in defining ideal treatment option may be related to wrong diagnosis. These problems persist until the pathogenesis and definite diagnosis have been established. For medical audit, we must deal with mild and severe cases. The patients with highly localized lesion such as calcific changes and bicipital tendinitis were excluded. It is concluded that no treatment is by far cheapest alternative and prospective trials shows that no treatment option is better than placebo. So we consider that all orthopedic surgeon uses one or the other option for treatment of stiff painful shoulder. Our cost and benefits analysis is relating to our own hospital. Similarly, the regular physiotherapy session too influences cost. Our results showed that local steroid injections are as effective as physiotherapy alone or combination of both. It provides rapid treatment and less expensive. ${ }^{20-22}$

\section{CONCLUSION}

Corticosteroid Injection Therapy was more effective in improving Impingement Syndrome of shoulder than that of Physical Therapy Treatment. Copyright $\odot 15$ May, 2019. 


\section{REFERENCES}

1. Huisstede BM, Miedema HS, Verhagen AP, Koes BW, Verhaar JA. Multidisciplinary consensus on the terminology and classification of complaints of the arm, neck and/or shoulder. Occupational and environmental medicine. 2007; 64(5): 313-9.

2. Greving K, Dorrestijn O, Winters JC, Groenhof F, van der Meer K, Stevens M, et al. Incidence, prevalence, and consultation rates of shoulder complaints in general practice. Scandinavian journal of rheumatology. 2012; $41(2): 150-5$.

3. Gruson KI, Ruchelsman DE, Zuckerman JD. Subacromial corticosteroid injections. Journal of Shoulder and Elbow Surgery. 2008; 17(1): S118-S30.

4. Arroll B, Goodyear-Smith F. Corticosteroid injections for painful shoulder: A meta-analysis. British Journal of general practice. 2005; 55(512): 224-8.

5. Gaujoux-Viala C, Dougados M, Gossec L. Efficacy and safety of steroid injections for shoulder and elbow tendonitis: A meta-analysis of randomised controlled trials. Annals of the rheumatic diseases. 2009; 68(12): 1843-9.

6. Koester MC, Dunn WR, Kuhn JE, Spindler KP. The efficacy of subacromial corticosteroid injection in the treatment of rotator cuff disease: A systematic review. Journal of the American Academy of Orthopaedic Surgeons. 2007; 15(1): 3-11.

7. Liu L, Huang QM, Liu QG, Ye G, Bo CZ, Chen MJ, et al. Effectiveness of dry needling for myofascial trigger points associated with neck and shoulder pain: A systematic review and meta-analysis. Arch Phys Med Rehabil. 2015; 96(5): 944-55.

8. Rhon DI, Boyles RB, Cleland JA. One-year outcome of subacromial corticosteroid injection compared with manual physical therapy for the management of the unilateral shoulder impingement syndrome: A pragmatic randomized trial. Ann Intern Med. 2014; $161(3): 161-9$.

9. Steurer J. Shoulder impingement syndrome: Steroid injections are not superior to manual physical therapy. Praxis. 1994; 103(23): 1408-9.

10. Roy JS, MacDermid JC, Woodhouse LJ. Measuring shoulder function: A systematic review of four questionnaires. Arthritis Care \& Research. 2009; 61 (5): 623-32.

11. Juniper EF, Guyatt GH, Willan A, Griffith LE. Determining a minimal important change in a disease-specific quality of life questionnaire. Journal of clinical epidemiology. 1994; 47(1): 81-7.
12. Fritz JM, Irrgang JJ. A comparison of a modified Oswestry low back pain disability questionnaire and the Quebec back pain disability scale. Physical therapy. 2001; 81(2): 776-88.

13. Jensen MP, Turner JA, Romano JM. What is the maximum number of levels needed in pain intensity measurement? Pain. 1994; 58(3): 387-92.

14. Jensen MP, McFarland CA. Increasing the reliability and validity of pain intensity measurement in chronic pain patients. Pain. 1993; 55(2): 195-203.

15. Chan A-W, Tetzlaff JM, Altman DG, Laupacis A, GÃ PC, Krle $\AA 3 / 4 a-J e r i \not ̈ ~ K$, et al. SPIRIT 2013 statement: Defining standard protocol items for clinical trials. Annals of internal medicine. 2013; 158(3): 200-7.

16. Zwarenstein M, Treweek S, Gagnier JJ, Altman DG, Tunis S, Haynes B, et al. Improving the reporting of pragmatic trials: an extension of the CONSORT statement. BMJ. 2008; 337.

17. Correction: Addition of lidocaine injection immediately before physiotherapy for frozen shoulder: a randomized controlled trial: PLoS One. 2015 Apr 15; 10(4): e0125289.

18. Abdulla SY, Southerst D, Cote P, Shearer HM, Sutton $D$, Randhawa $K$, et al. Is exercise effective for the management of subacromial impingement syndrome and other soft tissue injuries of the shoulder? A systematic review by the Ontario Protocol for Traffic Injury Management (OPTIMa) Collaboration. Man Ther. 2015; 20(5): 646-56.

19. Bateman M, McClymont S, Hinchliffe SR. The effectiveness and cost of corticosteroid injection and physiotherapy in the treatment of frozen shoulder-a single-centre service evaluation. Clin Rheumatol. 2014; 33(7): 1005-8.

20. Coombes BK, Vicenzino B. Pragmatic study of corticosteroid injections and manual physical therapy for the shoulder impingement syndrome. Ann Intern Med. 2014; 161(3): 224-5.

21. Dong W, Goost H, Lin XB, Burger C, Paul C, Wang ZL, et al. Treatments for shoulder impingement syndrome: a PRISMA systematic review and network metaanalysis. Medicine. 2015; 94(10): e510.

22. Esparza Minana JM, Londono Parra M, Villanueva Perez $V L$, De Andres Ibanez J. New options in the treatment of painful shoulder syndrome. Semergen. 2012; 38(1): 40-3. 


\begin{tabular}{|c|l|l|l|}
\multicolumn{4}{|c|}{ AUTHORSHIP AND CONTRIBUTION DECLARATION } \\
\hline Sr. \# & \multicolumn{1}{|c|}{ Author-s Full Name } & \multicolumn{1}{|c|}{ Contribution to the paper } & Author=s Signature \\
\hline 1 & Hafiz Salman Saeed & Study design, Article writing. & \\
\hline 2 & Muquduss Asif & Data collection \\
\hline 3 & Muhammad Sajjad lqbal & Concept \& Data analysis. \\
\hline 4 & Iqra Fayyaz & Proof reading \& Final subscript. & \\
\hline
\end{tabular}

